\title{
PENGARUH MOBILE APPS MYINDIHOME TERHADAP CUSTOMER ENGAGEMENT DI KOTA BANDUNG
}

Submitted Date :

12 Januari 2019

Accepted Date :

21 Januari 2019

\author{
Istiningrum \\ Universitas Telkom, Jl. Telekomunikasi, Indonesia \\ Istiningrum@student.telkomuniversity.ac.id \\ Diah Agung Esfandari \\ Universitas Telkom, Jl. Telekomunikasi, Indonesia \\ esfandari@telkomuniversity.ac.id
}

Kutipan yang disarankan:

Kotler Philip, Herman Kertajaya dan Iwan Setywan. 2016. Marketing 4.0: Moving from Traditional to Digital. Hoboken, New Jersey.

Abstrak:

Tujuan dari penelitian ini adalah untuk mengetahui seberapa besar pengaruh mobile apps MylndiHome terhadap customer engagement di kota Bandung. Metodologi yang digunakan dalam penelitian adalah kuantitatif dengan paradigma positivistik. Analisis data akan dilakukan menggunakan analisis deskriptif dan regresi liner sederhana. Hasil penelitian ini menunjukkan bahwa terdapat hubungan antara variabel $X$ dan variabel $Y$ termasuk ke dalam kategori hubungan sangat kuat. Dapat disimpulkan bahwa mobile apps MylndiHome mempengaruhi customer engagement sebesar $70,2 \%$ dan sisa sebanyak $29,8 \%$ dipengaruhi oleh faktor lain.

Kata Kunci: Mobile Applications, Customer Engagement

\section{Pendahuluan}

Hasil survei DDB, Nielson, dan Gerd Leonhard membuktikan bahwa masyarakat akan lebih percaya kepada rekomendasi dari teman-teman dan opini konsumen lain secara online dibandingkan dengan iklan konvensional. Maka dari itu, Customer Engagement berperan besar dalam mempertahankan konsumen lama agar dapat menjadi konsumen sekaligus pemasar. Seperti yang dikatakan Tripathi (2009), Customer Engagement adalah proses untuk mengembangkan, memelihara dan melindungi konsumen agar terus melakukan hubungan dengan perusahaan sehingga konsumen bukan hanya menjadi pembeli perusahaan bahkan melebihi dari sekedar pembeli yaitu menjadi pemasar bagi perusahaan.

IndiHome atau Indonesia Digital Home merupakan produk baru PT. Telkom (Tbk) yang muncul pada tahun 2015 dengan menawarkan produk triple-play. Mulai dari telepon, TV interaktif hingga internet dengan kecepatan mulai dari 10-100 mpbs Unlimited. Kebutuhan akan dunia internet yang semakin meningkat tentu mempengaruhi jumlah pelanggan IndiHome. Tahun 2018 sendiri, tercatat bahwa PT. Telkom Indonesia memiliki target 5,2 juta pelanggan pasang baru di seluruh Indonesia. Sedangkan menurut data terakhir pada 03 Desember 2018, Kota Bandung memiliki jumlah penggguna MylndiHome terbesar di Jawa Barat yang mencapai hampir $40 \%$ dari seluruh pengguna aplikasi MyIndiHome di Jawa Barat.

Di era digital ini, ada banyak sekali media yang dapat digunakan untuk meningkatkan Customer Engagement. Salah satunya melalui mobile apps yang mampu meningkatkan pengalaman digital pelanggan (kotler, 2016). Maka dari itu dengan banyaknya jumlah pelanggan, PT. Telkom Indonesia meluncurkan aplikasi seluler bernama MyIndiHome pada Maret 2016. Dengan tujuan untuk memudahkan pelanggan pasang baru, mencari ketersediaan layanan IndiHome, melihat berbagai info paket dan diskon terbaru, cek tagihan, dan melakukan laporan gangguan terhadap produk IndiHome. 
Marketing 4.0 menekankan kepada penggunaan marketing online yang diimbangi oleh penyelesaian offline oleh sebuah perusahaan. Sama halnya dengan penggunaan mobile apps MyIndiHome kepada pelanggan. Maka dari itu penting untuk mengetahui bagaimana platform yang digunakan sudah mampu memberikan dorongan pelanggan untuk sampai ke tahap advocate dan menjalin customer engagement yang baik. Strategi komunikasi pemasaran adalah Strategi dalam membentuk sebuah komunikasi dalam pemasaran dengan strategi promosi produk, ini akan menjadi bagian yang paling penting dalam mendorong suksesnya kegiatan pemasaran yang akan dilakukan. Promotion mix yang telah lama dikenal hanya iklan, promosi penjualan, publikasi/humas, dan personal selling. Namun George dan Michael Belch menambahkan dua elemen baru dalam, yaitu direct marketing dan interactive media (Morissan, 2010: 17-32). Sedangkan menurut philip kotler dan herman kertawijaya dalam bukunya marketing 4.0 (2016:153-155), ia menyebutkan bahwa ada beberapa cara untuk meningkatkan afinitas merek melalui mobile apps, CRM (customer relationship management), dan gamification. Mobile apps yang termasuk dalam interactive media menjadi salah satu cara baru untuk meraih pelanggan milenial yang masih bergantung besar pada smartphone dan membuka peluang untung membuat pelanggan tersebut menjadi pemasar baru. Melihat peluang besar pada strategi komunikasi pemasaran melalui mobile apps ini, peneliti tertarik untuk melakukan penelitian dan mencari kesempatan yang bisa dioptimalkan lagi nantinya. peneliti memilih untuk meneliti mobile apps Myindihome karena aplikasi ini dianggap mampu untuk mengatasi masalah pelayanan IndiHome yang lama dan membuka peluang baru untuk semakin sering diakses kemudian menjadi platform baru untuk melakukan promosi di era marketing 4.0 .

Urgensi yang ingin peneliti sampaikan adalah bagaimana dunia internet dan pemasaran yang dengan mudah bergerak secara dinamis, dapat menimbulkan suatu kesempatan untuk menumbuhkan cara pemasaran baru melalui pelanggan itu sendiri. Salah satu kunci untuk menjadikan pelanggan sebagai pemasar adalah dengan memperkuat Customer Engagement. Dengan banyaknya pelanggan dan touch point yang digunakan, IndiHome berusaha untuk mempertahankan pelanggan lama dan terus menambah jumlah pelanggan baru sesuai target melalui mobile apps MylndiHome. Dari latar belakang diatas, peneliti tertarik untuk melakukan penelitian dengan judul "Pengaruh mobile apps Myindihome Terhadap Customer Engagement di Kota Bandung"

\section{Metodologi}

Penelitian menggunakan paradigma positivistik dengan metode penelitian kausal. Penelitian ini akan berfokus pada penduduk kota bandung yang sudah menjadi pelanggan selama 1 tahun terakhir dan menggunakan moblie apps MylndiHome. Menurut data terakhir pada 03 Desember 2018, manager plaza Witel Bandung menyampaikan bahwa pengguna mobile apps Mylndihome sebesar 101.235 ribu orang. Penelitian ini menggunakan teknik nonprobability sampling dengan sample 100 orang. Teknik analisis data menggunakan analisis deskriptif, uji asumsi klasik, analisis korelasi, regresi linier sederhana dan uji hipotesis.

Hasil Penelitian

Tabel 1 : hasil uji regresi Linier sederhana Coefficients $^{a}$

\begin{tabular}{|c|c|c|c|c|c|c|}
\hline & \multirow{2}{*}{ Model } & \multicolumn{2}{|c|}{ Unstandardized Coefficients } & Standardized Coefficients & \multirow[t]{2}{*}{$t$} & \multirow{2}{*}{ Sig. } \\
\hline & & $B$ & Std. Error & Beta & & \\
\hline & $\begin{array}{l}\text { (Constant) } \\
\text { VAR_X }\end{array}$ & $\begin{array}{l}3,334 \\
1,143\end{array}$ & $\begin{array}{r}1,683 \\
, 075\end{array}$ & ,838 & $\begin{array}{r}1,981 \\
15,198\end{array}$ & $\begin{array}{l}050 \\
, 000\end{array}$ \\
\hline
\end{tabular}

Sumber : hasil olahan peneliti 2018

diperoleh koefisien regresi $X$ sebesar 1,143 dan nilai konstanta sebesar 3,334. Dengan demikian persamaan regresi linier sederhana untuk peneliti ini adalah :

$Y=a+b X$

$Y=3,334+1,143 X$ 
Artinya kenaikan 1 satuan variabel Mobile Apps Myindihome akan menyebabkan variabel Customer Engagement mengalami kenaikan sebesar 1,143.

Tabel 2 : hasil uji korelasi

\begin{tabular}{|c|c|c|c|c|}
\hline \multicolumn{5}{|c|}{ Model Summaryb } \\
\hline Model & $\mathrm{R}$ & R Square & Adjusted R Square & Std. Error of the Estimate \\
\hline 1 & $838^{\mathrm{a}}$ & 702 & 699 & 3,10548 \\
\hline
\end{tabular}

Sumber : hasil olahan peneliti 2018

Setelah dilakukan uji korelasi, dapat diketahui bahwa nilai koefisien korelasi $(r)$ adalah sebesar 0.838 artinya variabel $\mathrm{X}$ memiliki pengaruh sebesar 0.838 terhadap variabel $\mathrm{Y}$.

Pengujian hipotesis menggunakan uji-t dengan rumus (Riduwan, 2016:137)

$$
\begin{aligned}
& t=\frac{r \sqrt{n-2}}{\sqrt{1-r^{2}}} \\
& \text { Keterangan : } \\
& \mathrm{r}=\text { Koefisien Korelasi } \\
& \mathrm{n}=\text { Jumlah Responden } \\
& \text { thitung }=\frac{0,988 \sqrt{100-2}}{\sqrt{1-0,88 \mathrm{~s}^{2}}} \\
& \mathrm{~T}_{\text {hitung }}=15,19413
\end{aligned}
$$

T tabel dengan ketentuan taraf kepercayaan $90 \%$ dan taraf signifikansi $\alpha=10 \%$ dan derajat kebebasan (dk=n2) adalah 1.66055. Nilai thitung adalah 15,19413 lebih besar dari nilai trabel. Maka H0 ditolak dan $\mathrm{H} 1$ diterima artinya terdapat pengaruh Mobile apps MylndiHome terhadap customer engagement di kota Bandung.

\section{Pembahasan}

Makna persamaan regresi linier sederhana :

1. Konstanta sebesar 3,334 dan bertanda positif menandakan bahwa variabel mobile apps Myindihome memiiki nilai sebesar 3,334 apabila variabel independen yaitu customer engagement tetap atau nol.

2. 1,143 artinya kenaikan 1 satuan dari variabel mobile apps Myindihome akan menyebabkan variabel customer engagement mengalami kenaikan sebesar 1,143..

Berdasarkan persamaan tersebut dapat ditarik kesimpulan bahwa variabel independen yakni mobile apps Myindihome berpengaruh positif terhadap variabel dependen yaitu customer engagement.

Berdasarkan hasil perhitungan yang dilakukan peneliti menggunakan software SPSS 24 dapat diketahui bahwa koefisien korelasi ( $r$ ) dari penelitian ini sebesar 0.838 yang dapat dilihat pada tabel 2 . Hasil perhitungan tersebut dapat diinterpretasikan ke dalam kategori sangat kuat karena berada pada rentang nilai $0,80-1,000$ (Sugiyono, 2011:231).

Adapun interpretasi koefisien korelasi dapat dilihat dalam tabel berikut: 
Tabel 3 : interpretasi koefisien korelasi

\begin{tabular}{ll}
\hline Interval Koefisien & Tingkat hubungan \\
\hline $0,00-0,199$ & Sangat Rendah \\
$0,20-0,399$ & Rendah \\
$0,40-0,599$ & Sedang \\
$0,60-0,799$ & Kuat \\
$0,80-1,000$ & Sangat Kuat \\
\hline
\end{tabular}

Sumber : Sugiyono, 2011: 231

Hal ini menunjukkan bahwa mobile apps Myindihome (variabel X) mempunyai pengaruh yang sangat kuat terhadap customer engagement (variabel Y).

Setelah dilakukan analisis korelasi dan diketahui bahwa mobile apps Myindihome (variabel X) mempunyai pengaruh yang sangat kuat terhadap customer engagement (variabel $Y$ ) maka dilakukan analisis koefisien determinasi untuk menyatakan besar kecilnya sumbangsih variabel $X$ terhadap variabel $Y$. Nilai koefisien determinasi $\left(R_{2}\right)$ dari penelitian ini adalah 0,702 (dapat dilihat pada tabel 2) sehingga dapat disimpulkan bahwa mobile apps Myindihome (variabel X) mempengaruhi 70,2\% terhadap customer engagement (variabel Y) dan sisa sebanyak $29,8 \%$ dipengaruhi faktor lain.

T tabel dengan ketentuan taraf kepercayaan $90 \%$ dan taraf signifikansi $\alpha=10 \%$ dan derajat kebebasan (dk=n2) adalah 1.66055. Nilai $t_{\text {nitung }}$ adalah 15,19413 lebih besar dari nilai $t_{\text {tabel. }}$. Maka $\mathrm{H} 0$ ditolak dan $\mathrm{H} 1$ diterima artinya terdapat pengaruh mobile apps MylndiHome terhadap customer engagement di kota Bandung.

\section{Kesimpulan}

Berdasarkan hasil analisis dan pengolahan data pada penelitian pengaruh mobile apps MylndiHome terhadap customer engagement di kota Bandung maka dapat disimpulkan bahwa terdapat pengaruh mobile apps MyIndiHome yang menunjukkan bahwa hipotesis $\mathrm{H} 1$ diterima. Hasil penelitian ini juga menunjukkan bahwa terdapat hubungan antara variabel $X$ dan variabel $Y$. Hal tersebut dapat dibuktikan dengan nilai koefisien korelasi (r) sebesar 0.838 yang dapat diinterpresentasikan bahwa hubungan antara variabel $X$ dan variabel $Y$ termasuk ke dalam kategori hubungan sangat kuat. Nilai koefisien determinasi (R2) dari penelitian ini adalah 0,702 sehingga dapat disimpulkan bahwa mobile apps Myindihome (variabel X) mempengaruhi 70,2\% terhadap customer engagement (variabel $Y$ ) dan sisa sebanyak 29,8\% dipengaruhi faktor lain. Saran akademis dari peneliti untuk penelitian selanjutnya diharapkan dapat meneliti customer experience dan saran praktis dari peneliti agar aplikasi Mylndihome sering untuk melakukan update dan terus memberikan pemberitahuan pop-up agar pelanggan dapat dengan mudah aware terhadap promo yang berlangsung tanpa harus mencari tahu dan diharapkan semua promo disajikan dengan tampilan yang menarik agar semua promo bisa tersampaikan.

\section{Daftar Pustaka}

Brodie, Roderick J., Linda D. Hollebeek, Biljana juric, and Ana llic. (2011), Customer Engagement : Conceptual Domain, Fundamental Propositions and Implications for Reasearch. Journal of Service Research, 14 (3), 252-271.

Kotler Philip, Herman Kertajaya. (2016). Marketing 4.0. Hoboken, New Jersey.

Morissan. 2010. Periklanan: Komunikasi Pemasaran Terpadu. Jakarta: Prenadamedia Group Revisi IV. Jakarta: PT Rineka Cipta.

Patterson, P., Yu T, de Ruyter K. (2006). Understanding Customer Engagement Services : Advancing Theory, Maintaining Relevance. Preceedings of ANZMAC Conference

Riduwan. (2010). Metode dan Teknik Menyusun Tesis. Bandung : Alfabeta.

Sugiyono. (2014). Metode Penelitian Pendidikan Pendekatan Kuantitatif, Kualitatif, dan R\&D. Bandung: Alfabeta. Sugiyono. 2011. Statistika untuk Penelitian. Bandung : Alfabeta. 
Vivek, S.D., Beatty, S.E. dan Morgan, RM. (2011). Customer Engagement: Conceptual Domain, Fundamental Propositons, and Implications for Research, Journal of Service Research, 14: 252-271. 